\title{
Investigating Motivation among Libyan High School Students
}

\author{
Amal Saleh Sase ${ }^{1}$, Noureldin Mohamed Abdelaal ${ }^{1} \&$ Nahid Salih Amhimmid ${ }^{1}$ \\ ${ }^{1}$ Faculty of Modern Languages and Communication, Universiti Putra Malaysia \\ Corresponding author: Amal Saleh Sase, Faculty of Modern Languages and Communication, Universiti Putra \\ Malaysia.E-mail: saseamal@yahoo.com
}

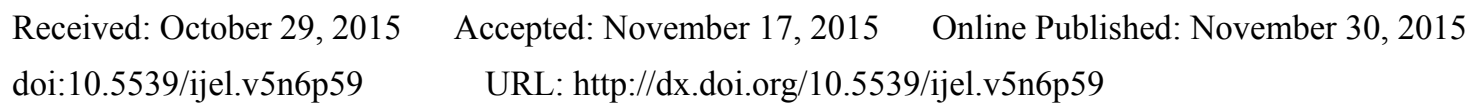

\begin{abstract}
There are many factors that are likely to affect the acquisition of English as a second or foreign language; among the most important affective factors is motivation. This study examined instrumental and integrative motivations among Libyan high school students in Kajang, Malaysia. It investigated whether EFL Libyan students are instrumentally or integratively motivated to study English, and the relationship between gender and type of motivation. This study adopted a qualitative approach through employing focus group interview. The findings of the study revealed that students are more integratively motivated than instrumentally. However, female students are more integratively motivated than male students are.
\end{abstract}

Keywords: gender, motivation; instrumental, integrative, Libyan students

\section{Introduction}

\subsection{Statement of the Problem}

There are many factors that influence second language learning and acquisition and they, according to Shoebottom (2007), are age, personality, motivation, experience, cognition and native language. However, in this study, we are going to look closely at motivation and how it plays a vital role in the learner's achievement. According to Liuoliene and Metiuniene (2006), "motivation is often attributed with the capacity to override other factors, such as language aptitude, to affect achievement in both negative and positive ways." (p. 93).

The term motivation in a second language learning context is seen according to Gardner (2007) as "referring to the extent to which an individual works or strives to learn the language because of a desire to do so and the satisfaction experienced in this activity". Since motivation is the drive that triggers effort to succeed in learning a second language, it is important to study such concept deeply. Melendy (2008) views motivation as the behavior that makes people (i.e., learners) achieve their goals. Further, motivation plays a key role in all walks of life. For example, a teacher cannot do his job well if he is not motivated enough to do his job as perfect as he can. For students, motivation sounds more important because some research and previous case studies (e.g., Ushida, 2005; Lett \& O'Mara, 1990) have shown correlation between motivation and second language acquisition. Motivation is the process that energizes, directs and sustains behavior (Santrock, 2011). Harmer (1991) claimed that motivation is the "internal drive" that pushes someone to do something, and the effort invested to achieve or to initiate L2 learning and to sustain such achievement (Ortega, 2008). In second language acquisition (SLA), motivation has been recognized as one of the important factors in verifying second language (L2) achievement and attainment (Lucas, Pulido, Miraflores, \& Ignacio, 2010). Gilakjani (2012) believes that motivation is such an important factor to the degree that other considerations about teaching methodology become irrelevant if there is no motivation at play.

Broadly speaking, there are two types of motivation; namely, instrumental and integrative motivations. Undoubtedly, both instrumental and integrative motivations are fundamentals of success in second language learning. Over the past few years, many studies have examined the relationship between motivation and second language acquisition. Most of them, though not all, showed a positive correlation between motivation and second language acquisition. However, this study has been conducted on Libyan students in Malaysia, and who are different from those in Libya due to many reasons: they live distant from their home; moreover, their access to internet, tablets and smart phones is assumed wider than their counterparts. They use them to connect with their friends and to connect with the whole world, especially with Facebook, twitter and the different social networks. Based on all that, it is predicted that the Libyan students are motivated to learn English, as they use it to connect 
with the international social network. Moreover, they utilize it to communicate with non-Arabs in a non-Arabic speaking environment such as Malaysia. Although literature shows superfluity in studies conducted on undergraduate students, not so many studies have been conducted on younger participants, the teenage group. This group age is characterized by open horizon and dreamy world which makes them have different prospects and motivations to learn English, such having friends from the English speaking community. Therefore, this study has been conducted to identify the type of motivation that exists among Libyan high school students in Malaysia, and the relationship between gender and motivation.

\subsection{Objectives}

This study specifically aims to:

1) Identify whether Libyan high school students in Malaysia are instrumentally or integratively motivated to learn English.

2) Investigate the relationship between gender and motivation.

\subsection{Research Questions}

1) What type of motivation is found among Libyan high school students?

2) Who are more motivated, girl students or boy students?

3) Does living in a country where English is spoken widely motivate students to learn English?

\subsection{Scope of the Study}

This study was conducted on 10 students, and which is considered as reliable sampling for a qualitative research. It was conducted in a Libyan school in Malaysia. However, different and larger sampling may yield different findings.

\section{Literature Review}

\subsection{Importance of Motivation}

Noteworthy to mention that with so many discouraging elements to English learning, like lack of English input in the environment, absence of opportunities to interact with English speakers, shortage of strong role models promoting the learning of English, and the social acceptance to the idea of becoming proficient in English, motivation has become more principal in second language learning (Gilakjani, 2012). In second language learning context, motivation determines the success or failure of a student. It also influences students' ability to learn quickly, as motivation invigorates them to get the concept faster than those who are not motivated. With the absence of motivation, students become less attentive, and they are likely to misbehave and cause discipline problems. The result however, will be the opposite when there is motivation; with students paying full attention to the lesson and participating actively in the learning activities.

\subsection{Types of Motivation}

There are different ways of categorizing motivation, though they mostly meet in a nutshell at the end. In the following lines, light is shed on these types of motivation.

\subsubsection{Short-Term and Long-Term Goal}

Harmer (1991, p. 3) divides motivation, according to the goal of such motivation, into two types: short-term goal and long-term goal. Short-term goal is defined as a wish to succeed in doing something in the near future. For example, in second language learning context, students learn English in the class very hard, so that they can get an "A" in their English examination. Conversely, long-term goal is a goal that involves constant efforts on something to get outcomes that can be utilized continuously, as when students learn English in the class very hard so that they can interact with other people who use English.

\subsubsection{Integrative and Instrumental Motivation}

Krashen (1988) proposed different categorization of second language learning motivation. He categorized motivation into integrative motivation and instrumental motivation. Integrative motivation happens when there is a desire to be a member or part of the community that speaks the second language. It is based on the sole interest to assimilate into that community. Sometimes, integrative motivation involves a great deal of affective factors relating to the community (Saville-Troike, 2006). For example, a student who is working hard to improve his English, his motivation can be the desire that he wants to interact with the American family next door and be submerged into the American culture, which he is fascinated with. On the other hand, instrumental motivation occurs in the works of practical values, such as increasing learners' career opportunities, or plainly passing a 
subject in the school (Saville-Troike, 2006).

\subsubsection{Intrinsic and Extrinsic Motivation}

Another school of thought divides motivation into intrinsic motivation and extrinsic motivation. Intrinsic motivation refers to the internal motivation to do something for its own sake; in other words, the effort itself is the objective (Santrock, 2011). Intrinsic motivation has no negative impact, as students learn because they innately want to, regardless of the external outcomes, such as reward or punishment, which does not affect the students' interest. An example of intrinsic motivation occurs when students write a long essay in an English examination paper because they enjoy writing, paying no mind to whatever marks they may get later. Extrinsic motivation, on the other hand, refers to the external motivation to do something to obtain something else; in other words, the effort is done to achieve an objective (Santrock, 2011). Extrinsic motivation may bring a negative impact, as students are likely to be driven by external outcomes. If the external outcomes are taken away, students' interest, as a result, disappears. For example, students write a long essay in the English examination paper because they want get higher marks. Nevertheless, if the marks are of no concern, where the examination is just a writing exercise, the students will only write what is required.

In sum, in a way, all these motivation types are interrelated to one another. It can be seen clearly that long-term goal, integrative and intrinsic motivation are perpendicular as how short-term goal, instrumental and extrinsic motivation are in a straight line. For example, when students are internally interested in English because of their interest to the culture, they are integratively, as well as intrinsically, motivated. Because of the interest, the second language learning becomes a long-term goal. However, when students are only learning the second language because they want to get better grades, so that they can join a good university with a scholarship, followed by getting a high-paying job, their motivation is extrinsic and instrumental. Getting better grades, getting into a good university with a scholarship and getting a high-paying job are short-term goals.

\subsection{Previous Studies}

Literature in the second language motivation was mostly focused on adult students. For example, Zanghar (2012) conducted a study to examine instrumental and integrative motivations among undergraduate Libyan students of English as a foreign language (EFL). The study investigated whether EFL Libyan students are instrumentally or integratively motivated to study English. The study also looked at the relationship between EFL Libyan students' motivation and their achievement in English. Forty Libyan students studying English as a foreign language at the college of Arts in BaniWalid, Libya, participated in the study. The participants were in different levels of their four-year university program as ten students were chosen from each year. All of the participants completed a questionnaire that included 14 items reflecting their instrumental and integrative motivations for studying English. The findings of the study showed that EFL Libyan students were highly instrumentally as well as integratively motivated to study English, and that their integrative motivation appeared to be a little higher than their instrumental one.

Another study was conducted by Taguchi (2006) to investigate whether motivation is a predictor of learning, as it is commonly believed and the other factors that could contribute to learning. He conducted the study on 61 students of the $10^{\text {th }}$ grade, and 4 teachers from 4 different schools. The students' age ranges from 14 to 16 years old and the teachers' experience ranges from eight to ten years of teaching. Two instruments were used; the first one is pre- and posttests. They were selected from the text book the students were using. The second instruments were two measures of motivation; namely, Grade 10 students' motivation level was measured using two questions, besides observing classes using Communicative Orientation of Language Teaching (COLT) scheme. The study showed that the most powerful predictors of language gains were found in more implicit teachers' beliefs about their students' capacities and their expectations of their students' achievement. The teachers in this study who expected more of their students received more knowledge in spite of the low motivation level of their students possibly had. The study revealed that even if student are motivated towards the target language, this will not contribute much in their progress if the teacher does not expect much out them. Thus, if the study were continue longer, the motivation level of the student will elevate due to the goals teacher holds towards them. Consequently, in order to elevate students' motivation in their second language, or to make benefits of already motivated students, teachers need to show a great expectation towards what should be achieved in the short or long term run.

Liuolienè (2006) carried out a study, as well, to evaluate students'L2 learning motives and their influence on the pedagogical process. He used, as other researchers, a survey of references on the problem of language learning motivation as an instrument of his study. The study findings revealed that students' wishes and needs to work independently depend on their motivation, attitude and responsibility. The higher motivation is, the more 
autonomous learning students want to have in the learning process. It was also found that students' ability to study independently has a positive influence on their higher ESL achievements. Thus, Needs analysis should be given considerable attention in making a particular course to serve a particular group's interests.

Ming et al. (2009) carried a study on Malaysian secondary students to identify the relationship between learning English as a second language and motivation. His study showed the existence of an overall positive attitude towards learning English among art and science students, though science students and higher proficiency students revealed more interest in improving their English. Furthermore, findings showed a positive relationship between a higher proficiency level and positive attitudes and motivation to learn English. The study showed that Malaysian students are extrinsically motivated rather than intrinsically. They mostly like to get their degrees hoping to pursue their career life with a better job.

\section{Methodology}

\subsection{Research Design}

This study adopts a qualitative method. A focus group interview as a qualitative tool was utilized.Interviews give in-depth understanding of the problem under study. The Interview has been utilized as an instrument in this study to deeply understand what type of motivation Libyan students have towards learning English. The interview aimed also at understanding the gender effect on the type of motivation. To achieve these goals five (5) female students and five (5) male students were interviewed. The interview was conducted in Arabic, their mother tongue, to have results that are more reliable. Then interviews were transcribed and translated into English.

\subsection{Instrument}

The instrument used in this study was a focus group interview. The interview questions included some guiding questions as:

1) Do you like to learn English? Why?

2) Do you mix up with friends in English?

3) Do you have non-Arab friends? In what language do you communicate with them?

4) Do you watch American movies?

5) Do you have online British or American friends? If yes, do you like them? Do you like to speak to them a lot?

6) Do you go out and mix with non-Arabs?

However, the aforementioned questions did not include all the questions suggested for discussion during the interview. There were some follow-up questions to understand if the participants have instrumental or integrative motivation. In addition, the first question addressed the study more broadly, as the motives behind learning English can convey whether the participants are instrumentally or integratively motivated. The participants were allowed to converse freely under guidance of the researchers.

\section{Findings and Discussion}

\subsection{Introduction}

Recapitulating the objectives of the study, it basically aimed at identifying whether Libyan high school students in Malaysia are instrumentally or integratively motivated to learn English, and the relationship between gender and motivation. The result of the interview showed that Libyan high school students in Malaysia are highly integratively motivated. Both the male and female participants expressed their high integrative motivation to learn English. As regards gender, female students had high integrative motivation to learn English rather than male students. They like to learn English to communicate with their friends from other nationalities, as most of them have friends from different parts of the world, and who do not speak Arabic. The reasons behind their desire to learn English can be summarized in the following themes:

\subsection{Female Students}

\subsubsection{Communication}

Female students like to learn English to communicate with their friends who are from different countries. They feel that English is an international language that is spoken by most people. For example, one of them said: "I like to learn English because it is useful to me so I can speak to different people by using English as a communication language tool." Another female student explains why she wants to learn English by saying: "I like to learn English because it helps me to ask and answer questions easily to others who do not speak Arabic 
as we do."

\subsubsection{Friendship}

Although Libyan girls are somehow culturally constrained, they still have friends who do not speak Arabic, so they need to learn English to communicate with them. They feel that speaking English will give them more chance to have friends from different countries. One of the interviewed girls; for example, said: "I mix with a non-Arab friend, she is my neighbor. She is from Russia and her name is Ameera. She is my friend and I speak with her in English every day, she is my close friend" While another girl said: "I mix up with others and my English language is improving because I have a lot of friends from different Malaysian races as Indian and Malays and Chinese. My friends' names are Chen Fei, RwshaKrshman and Nordia."

\subsubsection{Watching English-Medium Programs}

Watching TV programs like cooking shows, game shows, and movies constitute motivation for Libyan female students to learn English. One of these girls; for example, said: "My mom and I like to watch cooking English channel and I like to watch any fantastic movies like Harry Potter." Likewise, another female student says: "I like to watch American movies and I learn language because I want to understand what it is all about; the most favorite movies I like to watch are romance movies." It is clear that they like watching American movies, and they want to learn English to understand the content of such movies.

\subsubsection{Social Networking}

Technology is widely used among teenagers to connect with other people. Libyan female students like to use Facebook, twitter, etc. to connect with their friends who are non-Arab. They enjoy that in spite of the constraints imposed by their parents. One of these female students said: "My mom checks my Facebook account but I have a lot of friends. I speak with them in English, and I use viber and Skype to chat and have fun with them." Another student said: "I have many accounts for all social networks. I want to know about others' culture and learn from them. I have a lot of friends, and by using English I could have more and more friends who share with me their experiences and culture." Another female student said: "I have Skype and Facebook to chat with my friend; technology makes the world small and using English in the social networks help us have friends from all over the world." Another female student said: "My parents do not allow me to have my own accounts, so I am using my mom account to speak with my friends. I can say that my English is getting to be good from communication with others sometimes I am using YouTube to teach me how to express this. I want to speak and chat in English a lot of time because we are not in Libya and we have to improve our English and see the world in English eyes not Arabic eyes." All in all female students expressed high integrative motivation to learn English. They speak from heart about their desire to learn English to be able to communicate, have friends, and to know about others' culture. They did not mention any kind of instrumental motivation.

\subsection{Male Students}

Male students, surprisingly and likewise female students showed high integrative motivation. However, unlike female students, they reflected instrumental motivation. The main themes, which stand behind the male students' motivation to learn English can be put in the following lines:

\subsubsection{Short Goal and Long-Run Objectives (Instrumental Motivation and Integrative Motivation)}

Some students like to learn English for short goal objectives like to study and pass the courses he takes at school. For example one of them said: "We like to learn the language so we can make others understand our ideas and it is very important for us to learn English because now all the science subjects in English, so I have to earn English to pass the exams." He wants to learn English to study his scientific courses, which are in English. This conveys instrumental motivation. He also expressed his desire to learn English to understand others, which is integrative motivation. It seems that he has instrumental as well as integrative motivation. Another student said: "My dad told me the importance of learning English. All people around us are not Arab; however, we have to speak with them in English so they can help me, teach me and play with them." This indicates integrative motivation as well as instrumental motivation. It is integrative in the sense they want to learn English to be able to communicate with others. However, it is simultaneously instrumental in the sense that they need to learn English for short time purpose; that is, to communicate with the people around them.

\subsubsection{Long Term Objectives (Future Career) (Instrumental Motivation)}

Some male students showed their desire to learn English is because they are seeking a better job, and better future career. One of these students said: "To have good future and good career in Libya you have to speak English and other languages; my dad told me that if I work as a translator from English to Arabic in Libya, my 
salary will be higher. I hope I can be fluent." As seen in the student's quotation, he wants to learn English to find a better job opportunity.

\subsubsection{Communicative Purpose (Integrative Motivation)}

Male students showed also integrative motivation to learn English to communicate with others. One of the respondents said: "I have a lot of Pakistani friends whom I play football with every week, they speak English to me and I wish I can speak like them." Moreover, another student said: "I have a lot Malay and Chinese friends; I speak with them in English, so my language will improve."

\subsubsection{Culture: Movies, Drama (Integrative Motivation)}

Teenage students usually like watching drama and movies. The interview analysis showed that male students like to learn English to be able to watch movies. One of the respondents expressed that: "I like to watch action movies; all the time I try to catch their pronunciation when they speak." Similarly another student said: "I like to watch horror movies; sometimes I watch them on YouTube, so I can repeat again what I want to listen I can say that movies help me to speak English better."

\subsubsection{Social Networking (Integrative Motivation)}

Male students expressed their intrinsic desire to learn English to communicate with others who do not speak Arabic. One of these students said: "I use all social networks to speak the English language better. I have a lot of friends all over the world who speak English with me. I use Skype and Facebook to communicate with them." Likewise, another student said: "I have Viber, WhatsApp up and Facebook and I have a lot of friends speak English. I want to enhance my English level."

To conclude, female students showed higher integrative motivation than male students did. This may be thanked to the nature of girls in the Arab world. They like staying home, chatting with friends, and socializing. They do not look forward to having a job, with few exceptions. Conversely, and unsurprisingly male students showed balanced integrative and instrumental motivation. It is normal at this young age to find male students like speaking a second language, and socializing with friends. Arab students usually have early feeling of responsibility; they aspire to have a good job to help their families and to be prestigious among their folks.

As it has been presented above, the study revealed that students are more integratively motivated than instrumentally. This can be due to the age group, as students at this age do not consider a better job opportunity. They are not looking for promotion at workplace. Therefore, it is no wonder that students have high integrative motivation. The environment or society may have played a role, as well. Libyan students live in a non-Arabic speaking society; hence, they naturally need to communicate with Malaysian and non-Malaysian people in a shared language. They want to learn English to communicate with non-Arabs in a good way. This study is consistent with the results of other studies which have been carried on students from Japan (Mori \& Gobel, 2006) and from Iran (Ghazivini \& Khajehpour, 2011). However, what makes this study different is that it employed qualitative method which results in deeper understanding of the issue.

\section{Conclusion and Suggestions}

The present study had two objectives. The first objective was to identify whether Libyan high school students in Malaysia are instrumentally or integratively motivated to learn English; and the second objective was to investigate the relationship between gender and motivation. Interview was used as an instrument to answer these objectives. The interview thematic analysis revealed that Libyan female students are more integratively motivated than male students, and that both of the male and female students are more integratively motivated than instrumentally.

Future studies are suggested to employed mixed method approach to examine motivation among teenage students. It is also suggested that future studies be conducted on large sampling.

\section{References}

Gardner, R. C. (2007). Motivation and Second Language Acquisition 1. Porta Linguarum, 8, 9-20. http://doi.org/10.1017/S0272263102224067

Ghazvini, S. D., \& Khajehpour, M. (2011). Attitudes and motivation in learning English as second language in high school students. Procedia - Social and Behavioral Sciences, 15, 1209-1213. http://doi.org/10.1016/j.sbspro.2011.03.264

Gilakjani, A. P. (2012). The Significant Role of Multimedia in Motivating EFL Learners' Interest in English Language Learning. International Journal of Modern Education and Computer Science, 4(4), 57-66. 
http://doi.org/10.5815/ijmecs.2012.04.08

Harmer, J. (1991). The Practice of English Language Teaching. London: Longman.

Krashen, S. D. (1988). Second Language Acquisition and Second Language Learning. Pidginization and Creolization as language acquisition. Language Learning, 60(1), 154-193. http://doi.org/10.1111/j.1467-9922.2009.00554.x

Lett, J., \& O'Mara, F. E. (1990). Predictors of success in an intensive language learning context: Correlates of language learning at the defense language institute foreign language center. In T. S. Parry \& C. W. Stansfield (Eds.), Language aptitude reconsidered (pp. 222-260). Englewood Cliffs, NJ: Prentice Hall Regents.

Liuolienė, A., \& Metiūnienè, R. (2006). Second language learning motivation. Language Learning, 7(2), 93-98. http://doi.org/10.1111/j.1467-1770.1956.tb01198.x

Lucas, R., Pulido, D., Miraflores, E., \& Ignacio, A. (2010). A study on the intrinsic motivation factors in second language learning among selected freshman students. Philippine ESL Journal, 4(February), 3-23.

Melendy, G. (2008). Motivating writers: The power of choice. The Asian EFL Journal, 10(3), 187-198. Retrieved from http://www.asian-efl-journal.com/September_08_gm.php

Ming, T. S., Ling, T. S. \& Nurjanah, M. J. (2011). Attitudes and motivation of secondary students towards learning English as a second language: a case study. 3L: The Southeast Asian Journal of English Language Studies, 17(1), 40-54. Retrieved from http://journalarticle.ukm.my/2047/

Ortega. L. (2008). Understanding Second Language Acquisition. New York: Routledge.

Santrock, J. W. (2011) . Educational Psychology. NY: McGraw Hill.

Saville-Troike, M. (2006). Introducing second language acquisition. Foundations (Vol. 4).

Shoebottom, P. (2007). How to learn Vocabulary. Retrieved from http://esl.fis.edu/learners/advice/vocab.htm.

Taguchi, K. (2006). Is motivation a predictor of foreign language learning? International Education Journal, $7(4), 560-569$.

Taguchi, K. (2006). Is motivation a predictor of foreign language? International Education Journal, 560-570. Retrieved from http://files.eric.ed.gov/fulltext/EJ854311.pdf

Ushida, E. (2005). The Role of Students' Attitudes and Motivation in Second Language Learning in Online Language Courses. CALICO Journal, 1(23), 49-78. http://doi.org/10.1111/j.1467-1770.1956.tb01198.x

Zanghar, A. (2012). Instrumental and integrative motivation among undergraduate Libyan students of English as a foreign language (pp. 1-65). Retrieved from http://digitool.library.colostate.edu/exlibris/dtl/d3_1/apache_media/L2V4bGlicmlz

\section{Copyrights}

Copyright for this article is retained by the author(s), with first publication rights granted to the journal.

This is an open-access article distributed under the terms and conditions of the Creative Commons Attribution license (http://creativecommons.org/licenses/by/3.0/). 